\title{
Baicalein Inhibits Dextran Sulfate Sodium-induced Mouse Colitis
}

\author{
Xiancai Zhong ${ }^{1}$, Young-Joon Surh ${ }^{1,2}$, Seon-Gil Do ${ }^{3}$, Eunju Shin ${ }^{3}$, Kyu-Suk Shim ${ }^{3}$, Chong-Kil Lee ${ }^{4}$, Hye-Kyung Na ${ }^{5}$ \\ ${ }^{1}$ Tumor Microenvironment Global Core Research Center and Research Institute of Pharmaceutical Sciences, College of Pharmacy, Seoul National \\ University, ${ }^{2}$ Department of Molecular Medicine and Biopharmaceutical Sciences, Graduate School of Convergence Science and Technology, Seoul \\ National University, ${ }^{3}$ Univera Co., Ltd., Seoul, ${ }^{4}$ College of Pharmacy, Chungbuk National University, Cheongju, ${ }^{5}$ Department of Food Science and \\ Biotechnology, College of Knowledge-Based Services Engineering, Sungshin Women's University, Seoul, Korea
}

Background: Baicalein is a bioactive flavone that is originally extracted from the root of Scutellaria baicalensis Georgi. This plant has long served as Chinese herbal medicine in the management of multiple diseases including inflammatory bowel diseases. Although it has been revealed that baicalein inhibits experimental colitis in mice, the molecular mechanisms still remain largely unrecognized.

Methods: The experimental colitis was induced in mice by 3\% dextran sulfate sodium (DSS) in drinking water. The mice were given baicalein (10 or $25 \mathrm{mg} / \mathrm{kg}$ ) by gavage for 7 days before and after DSS administration. Expression of COX-2 and inducible nitric oxide

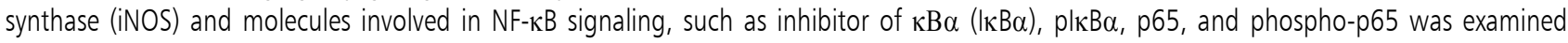
by Western blot analysis in the tissue of the mouse colon. Activity of $I_{\kappa} B$ kinase $\beta$ (IKK $\beta$ ) was assessed by measuring the relative amount of radioactive $\gamma$-phosphate of ATP transferred to the $I_{\kappa} B \alpha$ substrate protein. The expression and phosphorylation of STAT3 and its target gene cyclin D1 were also measured.

Results: Baicalein prominently mitigated the severity of DSS-induced colitis in mice. It inhibited the expression of COX-2 and iNOS. Moreover, baicalein attenuated activity and phosphorylation of $I K K \beta$ and subsequent degradation of $1 \kappa B \alpha$. Baicalein suppressed the phosphorylation and nuclear translocation of p65, resulting in a reduced DNA binding activity of NF-kB. Baicalein also suppressed the phosphorylation of STAT3 and expression of cyclin D1. Baicalein exhibited the synergistic effect on inhibition of COX-2 induced by DSS with curcumin, an ingredient of turmeric.

Conclusions: Protective effects of baicalein on DSS-induced colitis are associated with suppression of NF-KB and STAT3 signaling pathways, which may contribute to its cancer preventive effects on colon carcinogenesis.

(J Cancer Prev 2019;24:129-138)

Key Words: Baicalein, Colitis, NF-кB, Cyclooxygenase-2, Anti-inflammation

\section{INTRODUCTION}

Chronic inflammatory bowel disease (IBD), a disorder of colonic mucosa, has been implicated in the pathogenesis of colorectal cancer. Two major types of this disease encompass ulcerative colitis and Crohn's disease, with comparable signs including diarrhea and rectal bleeding. The development of this disease is associated with an imbalance of gut microflora and consequently inappropriate immune response [1]. COX-2 and inducible nitric oxide synthase (iNOS) are frequently overexpressed in inflammation-associated carcinogenesis. These two pro-inflammatory enzymes catalyze the generation of prostaglandin $\mathrm{E}_{2}$ and nitric oxide, respectively [2,3], leading to many oncogenic events [4,5].

Although acute inflammation protects host body against pathogens, foreign bodies or injury, chronic inflammation has been demonstrated an involvement in the development of cancer

Received June 17, 2019, Revised June 25, 2019, Accepted June 26, 2019

Correspondence to: Hye-Kyung Na

E-mail: nhkdec28@gmail.com, ORCID: Hye-Kyung Na, https://orcid.org/0000-0003-0460-2810

Correspondence to: Young-Joon Surh

E-mail: surh@snu.ac.kr, ORCID: Young-Joon Surh, https://orcid.org/0000-0001-8310-1795

Copyright (C) 2019 Korean Society of Cancer Prevention

(c) This is an Open Access article distributed under the terms of the Creative Commons Attribution Non-Commercial License (http://creativecommons.org/icenses/by-nc/4.0) which permits unrestricted non-commercial use, distribution, and reproduction in any medium, provided the original work is properly cited. 
[6]. In the progression of inflammation-associated cancer, a transcriptional factor NF- $\kappa \mathrm{B}$, has been identified as an essential factor involved in inflammation-associated cancer [7]. NF- $\kappa \mathrm{B}$ is activated upon stimulation by signals from pathogens or other stimuli at inflamed sites [8,9], thereby triggering expression of proliferative and anti-apoptotic genes [10]. Sustained inflammatory conditions, such as chronic IBD, activated NF-אB signaling, resulting in high risk for development of colon carcinogenesis [11]. Therefore, a constitutive overactivation of NF- $\kappa$ B is often observed in multiple cancers including colon cancer [12]. The constitutively activated NF- $\kappa \mathrm{B}$ may cause unresolved tissue repair and perturb growth of crypt stem cells, which mediates transformation of crypt stem cells into adenomas [13]. A subsequently accumulated reactive oxygen species, reactive nitric species and TNF accelerate the development of malignant tumor by causing loss of function of tumor suppressor genes [13], mutation of p53 [14,15] and epigenetic alterations [16].

$\mathrm{NF}-\mathrm{\kappa B}$ modulates the expression of proinflammatory enzymes (e.g., COX-2 and iNOS) in response to various stimuli, resulting in cellular transformation, proliferation, angiogenesis and metastasis [17]. Under physiological conditions, NF- $\kappa B$ is sequestered in the cytoplasm of cells by the inhibitor of $\kappa \mathrm{B}$ (I $\kappa \mathrm{B})$, thereby restricting the expression of those inflammation-related genes. Once I $\mathrm{B} \alpha$ is phosphorylated and subsequently degraded, p65/p50 heterodimer translocates into the nucleus for initiating transcription of genes [18]. The phosphorylation of $\mathrm{I} \kappa \mathrm{B} \alpha$ is dominantly carried out by I $\kappa B$ kinase $\beta$ (IKK $\beta$ ) [19]. The activity of NF- $\kappa B$ is dependent on the post-transcriptional modulations of the subunit p65, such as phosphorylation, acetylation and nitration [20]. STAT3 is another transcription factor that is also regulated by phosphorylation at the tyrosine 705 residue [21]. Aberrant STAT3 activation was found in patients with colonic diseases [22,23].

Baicalein is one of the principal bioactive components of Scutellaria baicalensis Georgi which is known as a Chinese herbal medicine (Huang Qin) for over 20 centuries [24]. It is noteworthy to investigate functions of this compound for safe treatment or prevention of various diseases. Many studies have demonstrated anti-oxidative [25], anti-inflammatory [26], and anti-tumor activities [27-29] of baicalein. Though the protective effects of baicalein on experimentally induced colitis [30-32] and intestinal carcinogenesis [33] have been reported, the mechanisms of baicalein against IBD remain to be comprehensively elucidated. In this study, we investigated whether baicalein could inhibit the development of colitis in mice upon dextran sulfate sodium (DSS) treatment, exploring its chemopreventive potential.

\section{MATERIALS AND METHODS}

\section{Materials}

DSS with an average molecular weight 36,000-50,000 Da was obtained from MP Biomedicals, LLC (Solon, OH, USA). Baicalein (5,6,7-trihydroxyflavone) with a purity of $98 \%$ was purchased from Sigma Aldrich Co. (St. Louis, MO, USA). COX-2 (murine) polyclonal antibody produced from rabbit was supplied by Cayman Chemical (Ann Arbor, MI, USA). Polyclonal rabbit anti-iNOS/NOS type II antibody was provided by BD Biosciences (Franklin Lakes, NJ, USA). Primary antibodies against cyclin D1, STAT3, pSTAT3, p65, and pI B $\alpha$ were offered by Cell Signaling Technology, Inc. (Danvers, MA, USA). Antibodies against ERK1/2,

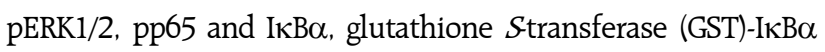
protein, normal mouse immunoglobulin $\mathrm{G}$ (IgG), and protein $\mathrm{G}$ plus-agarose were obtained from Santa Cruz Biotechnology, Inc. (Santa Cruz, CA, USA). Anti-actin antibody was from Sigma Aldrich Co. Horseradish peroxidase-conjugated anti-mouse and rabbit secondary antibodies were obtained by Zymed Laboratories (San Francisco, CA, USA). NF-кB oligonucleotide probe containing the consensus sequence (5'-AGT TGA GGG GAC TTT CCC AGG C-3', 3'-TCA ACT CCC CTG AAA GGG TCC G-5') was a product of Promega (Madison, WI, USA). STAT3 oligonucleotide probe containing the consensus sequence (5'-GAT CCT TCT GGG AAT TCC TAG ATC-3') was produced by Santa Cruz Biotechnology, Inc.. The enhanced chemiluminescence (ECL) detection kit and $\left[\gamma_{-}^{32} \mathrm{P}\right]$-ATP were provided by Amersham Pharmacia Biotech (Buckinghamshire, UK).

\section{Animals}

Five-week-old male ICR mice were obtained from Sankyo Lab service Co. (SLC, Tokyo, Japan) and housed in pathogen-free room in Seoul National University. All animal experiments were performed according to the guidelines from the Institutional Animal Use and Care Committee of Seoul National University. The approvement of the experimental protocol was carried out by the Animal Experimental Ethics Committee, Seoul National University (authorization number SNU-090501-3). After an acclimation for 5 days, mice were treated with either vehicle ( $0.05 \%$ carboxymethyl cellulose) or baicalein (10 and $25 \mathrm{mg} / \mathrm{kg}$ ) for one week to generate a preventive condition in mice. A following treatment of 3\% DSS in drinking water was performed to induce mouse colitis. For evaluation of the synergistic effect, mice were treated with baicalein $(25 \mathrm{mg} / \mathrm{kg})$, curcumin $(25 \mathrm{mg} / \mathrm{kg})$ or both compounds for indicated time. Mice were euthanized after 7 days of DSS treatment. 


\section{Macroscopic assessment}

During the treatment of DSS, the body weight of mice was measured daily. The severity of colitis was assessed following the criteria [34] with slight modification. In detail, the score of diarrhea or rectal bleeding (0-3 points) was determined based on extent of liquid stool and amount of blood, respectively. The severity of disease was reflected by a disease activity index (DAI) which was calculated as the sum of scores of stool consistency and rectal bleeding.

\section{Histological evaluation}

After treatment with DSS, mice were sacrificed, the colon parts were collected. Specimens of distal parts of the colon were fixed with $10 \%$ phosphate buffered formalin, and embedded in paraffin and stained with hematoxylin and eosin.

\section{Western blot analysis}

Mouse colon parts were cut longitudinally, washed with PBS, and stored at $-70^{\circ} \mathrm{C}$ until use. Colon tissues were homogenized in ice-cold lysis buffer (150 mM NaCl, 0.5\% triton-X 100, $50 \mathrm{mM}$ Tris-HCl [pH 7.4], 20 mM EGTA, 1 mM dithiothreitol [DTT], 1 $\mathrm{mM} \quad \mathrm{Na}_{3} \mathrm{VO}_{4}$ and protease inhibitors, $1 \mathrm{mM}$ phenylmethylsfonylfluoride [PMSF], and EDTA-free cocktail tablet) and implicated to a sufficient lysis by periodical vortex for 30 minutes. Lysates were centrifuged for 15 minutes at $4^{\circ} \mathrm{C}$. Collected supernatants were stored at $-70^{\circ} \mathrm{C}$ until use. For Western blot analysis, the concentration of total protein was quantified using the bicinchoninic acid protein assay kit. Cell lysates were separated by SDS-PAGE, and the proteins were transferred to PVDF membrane after mixing and heating with SDS buffer. The blots were blocked in 5\% fat free milk in PBS with $0.1 \%$ Tween-20 (PBST) at room temperature for 1 hour and incubated with primary antibodies. Membranes were then washed with PBST for 30 minutes and incubated with HRP-conjugated secondary antibodies for 1 hour. The target protein was incubated with an ECL detection kit and visualized with the LAS-4000 image reader (Fujifilm Life Science, Stamford, $\mathrm{CT}$, USA) on the basis of the manufacturer's instructions.

\section{Fractionation of nuclear and cytosolic extracts}

To obtain cytosolic and nuclear extracts, colon tissues dissolved in hypotonic buffer A (10 mM HEPES [pH 7.8], $1.5 \mathrm{mM}$ $\mathrm{MgCl}_{2}, 10 \mathrm{mM} \mathrm{KCl}, 1 \mathrm{mM}$ DTT, $0.1 \mathrm{mM}$ EDTA, and 0.1 mM PMSF) were homogenized followed by vortex mixing every 10 minutes for 3 hours. The mixture was centrifuged at $14,000 \mathrm{rpm}$ for 15 minutes. Nonidet P-40 (NP-40, 10\%) was supplemented to the mixture at 10 minutes prior to the centrifugation. The supernatants contain the cytosolic extracts were collected and stored at $-70^{\circ} \mathrm{C}$. Precipitated pellets were washed with buffer A plus $10 \%$ NP-40 for 3 times to remove remaining cytosolic components. Then pellets were re-suspended in buffer $\mathrm{C}(50 \mathrm{mM}$ HEPES [pH 7.8], $50 \mathrm{mM} \mathrm{KCl}, 300 \mathrm{mM} \mathrm{NaCl}, 0.1 \mathrm{mM}$ EDTA, $1 \mathrm{mM}$ DTT, $0.1 \mathrm{mM}$ PMSF, and 20\% glycerol). After centrifugation at $14,000 \mathrm{rpm}$ for 15 minutes, the supernatants (nuclear extracts) were collected and stored at $-70^{\circ} \mathrm{C}$.

\section{Electrophoresis mobility shift assay}

DNA binding activities of NF- $\mathrm{KB}$ and STAT3 were measured by electrophoresis mobility shift assay using a DNA binding detection kit according to the manufacture's protocol (Gibco BRL, Grand Island, NY, USA). In brief, the oligonucleotides harboring the consensus sequence were end-labeled with $\left[\mathrm{r}^{32} \mathrm{P}\right] \mathrm{ATP}$ using T4 polynucleotide kinase. After purification with a Nick column (Amersham Pharmacia Biotech), $\left[\gamma_{-}{ }^{32} \mathrm{P}\right]$ labeled probes were mixed with $20 \mu \mathrm{g}$ nuclear extracts and incubation buffer $(10 \mathrm{mM}$ Tris-HCl [pH 7.5], $100 \mathrm{mM} \mathrm{NaCl}, 1 \mathrm{mM}$ DTT, 1 mM EDTA, 4\% glycerol and $0.1 \mathrm{mg} / \mathrm{mL}$ sonicated salmon sperm DNA). All the samples were mixed with $2 \times$ bromophenol blue loading dye $(0.1 \% \mathrm{w} / \mathrm{v})$ after 50 -minute incubation and separated on $6 \%$ non-denatured polyacrylamide gel in a cold room. Finally, gels were dried and exposed to X-ray films.

\section{IкB kinase $\beta$ activity assay}

The IKK $\beta$ activity was measured with whole lysates according to the our previous studies [35]. Samples (200 $\mu \mathrm{g}$ ) were pre-cleared using normal mouse IgG and protein $G$ plus agarose beads. The immune-precipitation was performed by incubation with anti-IKK $\beta$ antibody and protein $G$ plus agarose beads. The precipitated pellets were re-suspended in $50 \mu \mathrm{L}$ reaction mixture containing $48 \mu \mathrm{l}$ kinase buffer ( $25 \mathrm{mM}$ Tris- $\mathrm{HCl}$ [pH 7.5], $5 \mathrm{mM}$ glycerophosphate, $2 \mathrm{mM}$ DTT, $0.1 \mathrm{mM} \mathrm{Na} \mathrm{VO}_{4}$, and $10 \mathrm{mM}$

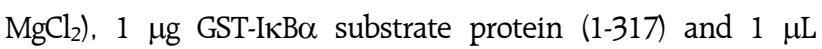
$\left[\gamma_{-}{ }^{32} \mathrm{P}\right]$-ATP followed by incubation at $37^{\circ} \mathrm{C}$ for 30 minutes. After adding $15 \mu \mathrm{L}$ SDS loading dye, heat block was performed at $99^{\circ} \mathrm{C}$ to stop kinase reaction. Samples were then separated by $12 \%$ SDS-PAGE, and the gel was stained with Coomassie brilliant blue followed by de-staining using de-staining solution (glacial acetic acid : methanol : distilled water $=1: 4: 5$ ). Gels were dried and exposed to X-ray film to detect phosphorylated GST-IкB $\alpha$ in the radiogram. 


\section{Statistics}

The data on bodyweight change expressed as the mean \pm SD. All the other values were expressed as the mean \pm SEM of at least two independent experiments. Statistical significance was determined by the Student's $t$-test using Graphpad Prism 7 program and $P<0.05$ was considered to be statistically significant.

\section{RESULTS}

\section{Baicalein ameliorated pathological symptoms of mice treated with dextran sulfate sodium}

To induce a colonic inflammation, we administrated male mice with 3\% DSS in drinking water for consecutive 7 days. Baicalein (10 mg/kg or $25 \mathrm{mg} / \mathrm{kg}$ ) was administered by gavage for 7 days before DSS treatment and the treatment was extended for another 7 days together with DSS treatment. We measured the bodyweight every day during the experiment period. We observed that mice treated with DSS lost body weight at the fourth day compared to mice in the control group. The oral administration of baicalein significantly attenuated body weight loss (Fig. 1A). We also scored the severity of rectal bleeding and diarrhea based on the fecal blood and stool consistency, respectively from 0 to 3 , and the sum was given into a form of the DAI. Mice in the DSS group exhibited serious symptoms with liquid stool and large amount of blood. Administration of baicalein ameliorated the severity of rectal bleeding and diarrhea (Fig. 1B).

\section{A}

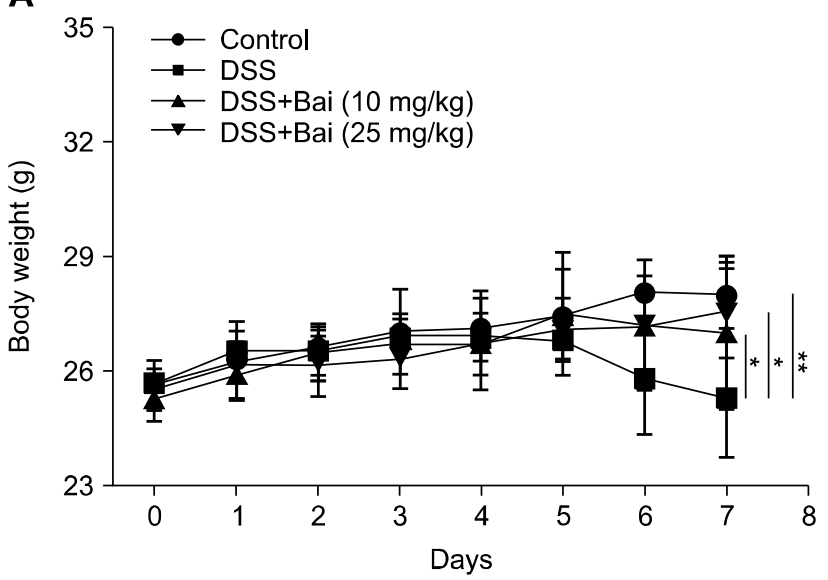

2. Baicalein attenuated dextran sulfate sodiuminduced expression of COX-2, inducible nitricoxide synthase, and cyclin D1

We performed histological evaluation of dysplasia in the colonic crypts using H\&E staining. As shown in Figure 2A, mice in the control group exhibited an intact crypt structure. This mucosal structure of distal colons was completely disrupted by DSS treatment. Moreover, an infiltration of inflammatory cells was observed in both layers of epithelial cells and lamina propria. Baicalein-treated mice partially maintained the integrity of colonic structure. Less inflammatory cells were observed in those colons from baicalein-treated mice. The severity of colitis was further assessed by measuring the level of intracellular proteins involved in inflammation. Baicalein inhibited the expression of COX-2, iNOS, and cyclin D1 in mouse colons (Fig. 2B and 2C). A higher dose of baicalein $(25 \mathrm{mg} / \mathrm{kg}$ ) exhibited a more pronounced effect on the expression of these markers.

\section{Baicalein abrogated activation of NF-KB signaling}

Since NF-KB is the most important transcription factor regulating a series of inflammatory processes, we determined the activation status of NF- $\mathrm{KB}$ in mouse colon. Administration of DSS resulted in a phosphorylation and subsequent degradation of I $\mathrm{B} \alpha$, and translocation of p65 into nucleus, while these events were abolished by baicalein administration (Fig. 3A). The activity of NF- $\mathrm{KB}$ is associated with the phosphorylation of p65. DSS enhanced the level of phosphorylated $\mathrm{p} 65$, which was attenuated by baicalein (Fig. 3A). IKK $\beta$ is the major kinase that regulates the

B

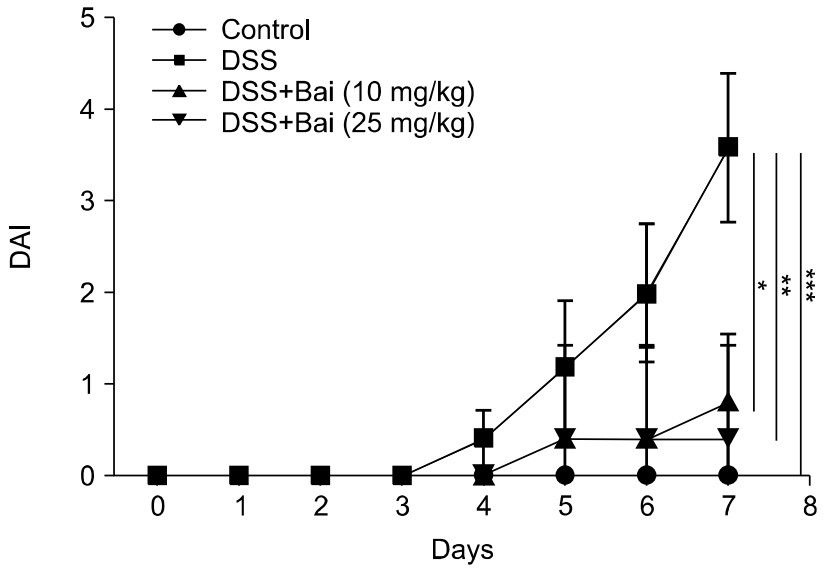

Figure 1. Macroscopic assessment of mice. Mice were treated with 3\% dextran sulfate sodium (DSS) in drinking water for 7 days with or without baicalein (Bai, 10 or $25 \mathrm{mg} / \mathrm{kg}$; per oral) administered during and after DSS treatment for another 7 days. (A) Body weight of mice was measured daily during the administration of DSS. (B) Stool consistency and rectal bleeding were measured according to the severity and given scores (0-3). A sum of those scores represents the disease activity index (DAI) for assessing the severity of disease. Values of body weight are presented as means $\pm \mathrm{SD}$ and DAI data were shown as means $\pm \mathrm{SEM}\left(* P<0.05,{ }^{* *} P<0.01,{ }^{* * *} P<0.001\right)$. 
A

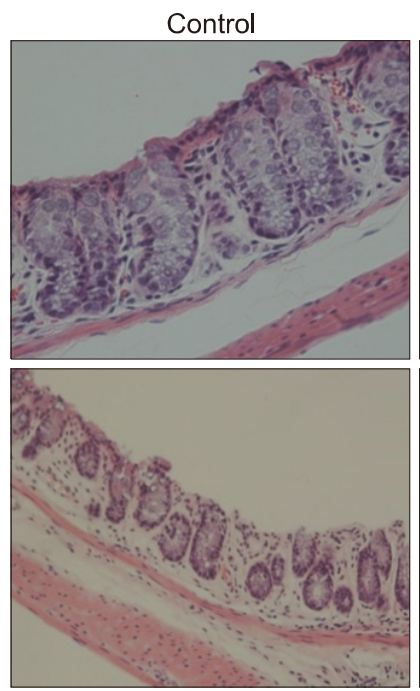

DSS+Bai $(10 \mathrm{mg} / \mathrm{kg})$

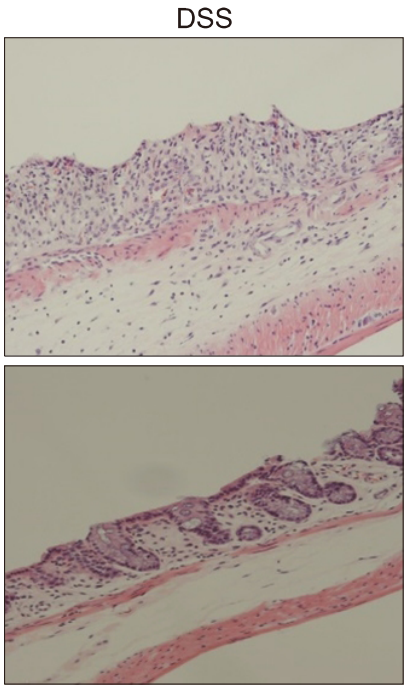

DSS+Bai $(25 \mathrm{mg} / \mathrm{kg})$
B

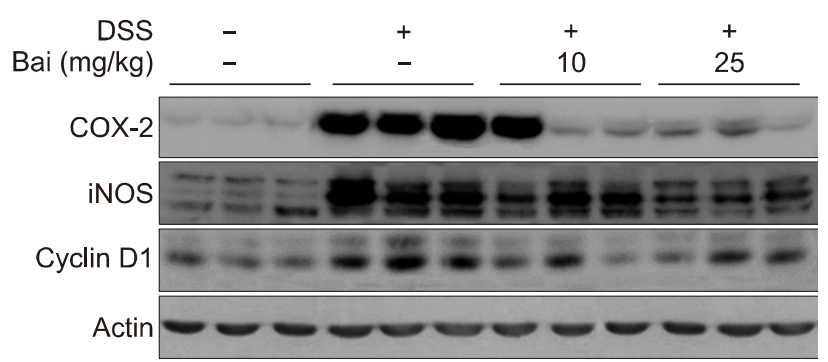

C
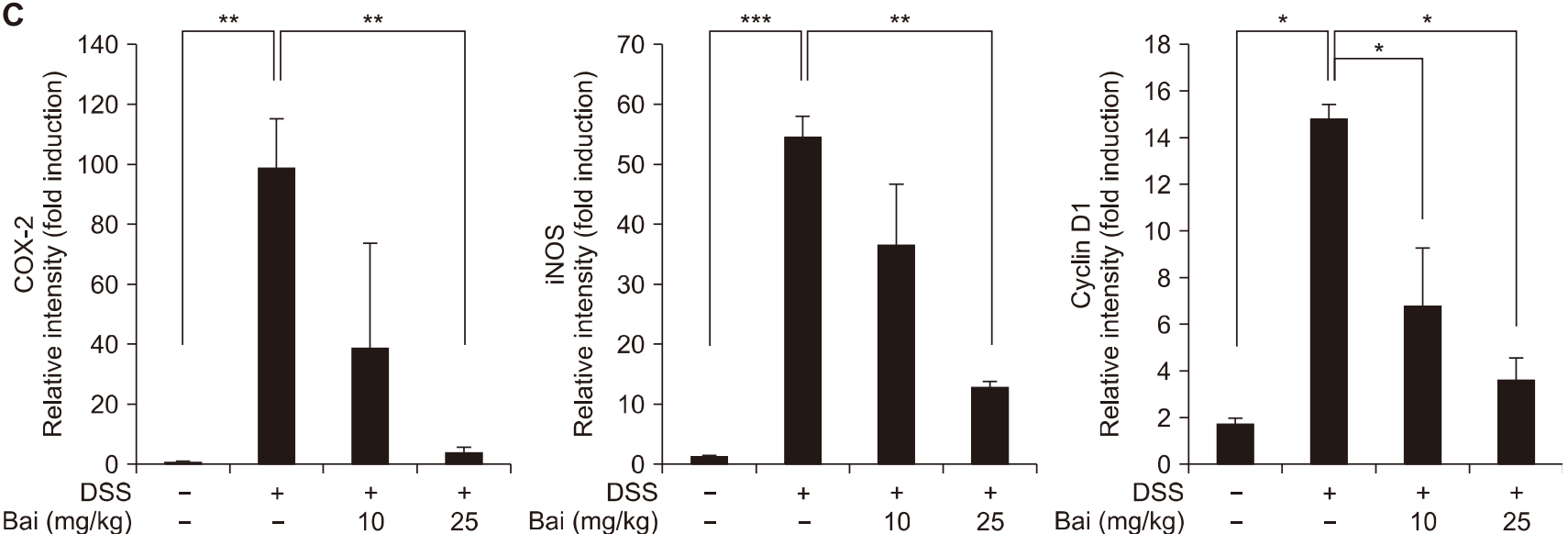

Figure 2. Effect of baicalein (Bai) on dextran sulfate sodium (DSS)-induced colitis. (A) Mouse colons were collected and distal parts were fixed with $4 \%$ phosphate buffered formalin, followed by a H\&E staining (10X). (B) After a longitudinal cutting, half of remaining colonies was applied to the whole protein extraction followed by Western blot analysis to detect COX-2, inducible nitric oxide synthase (iNOS), and cyclin D1. (C) The quantitative data are presented as means \pm SEM $(* P<0.05, * * P<0.01, * * * P<0.001)$.

phosphorylation of IKB $\alpha$, thereby mediating IBD and colitis-associated cancer [19]. Our data showed the activity of IKK $\beta$ in baicalein-treated mouse colons was significantly reduced compared to that in colons treated with DSS alone (Fig. 3B). The DNA binding activity of NF-KB was found to be attenuated in mice treated with DSS and baicalein compared to those treated with DSS alone (Fig. 3C).

\section{Baicalein suppressed STAT3 signaling}

NF-KB drives carcinogenesis through a crosstalk with STAT3, which contribute to inflammatory events including colitisassociated cancer [36]. Our result indicates that baicalein suppresses the activation of STAT3 by inhibiting its phosphorylation (Fig. 4A) and DNA binding (Fig. 4B).

\section{Baicalein shows synergistic effects with curcumin on dextran sulfate sodium-induced colitis}

Curcumin is a representative anti-inflammatory phytochemical with well-defined chemopreventive potential. Our previous studies have revealed that oral administration of curcumin inhibited DSS-induced activation of NF-KB [37] and STAT3 [38] in mouse colon, which may contribute to its protection against DSS-induced colitis. Co-administration of baicalein and curcumin inhibited IкB $\alpha$ degradation, STAT3 phosphorylation and COX-2 
A
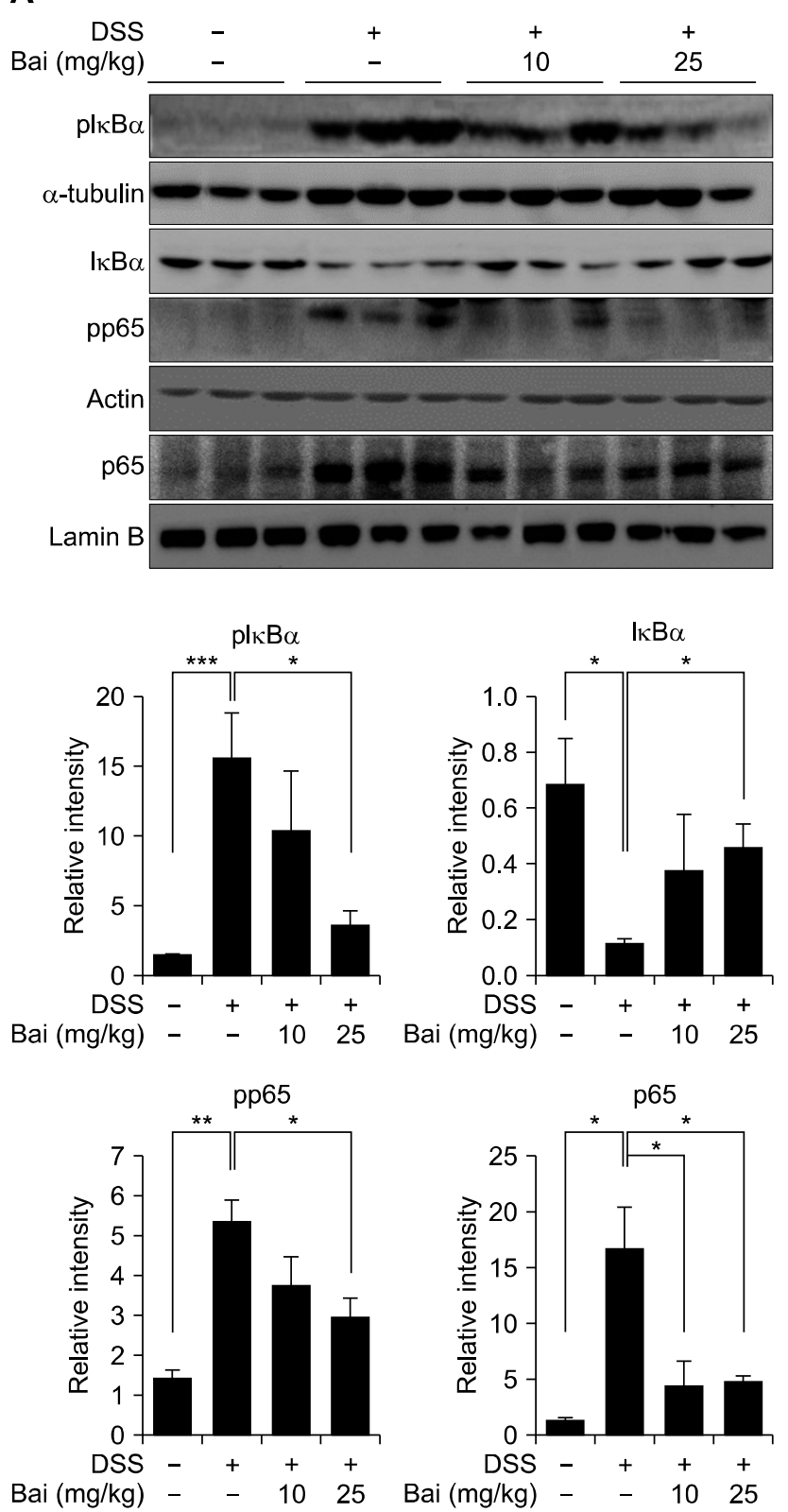

B

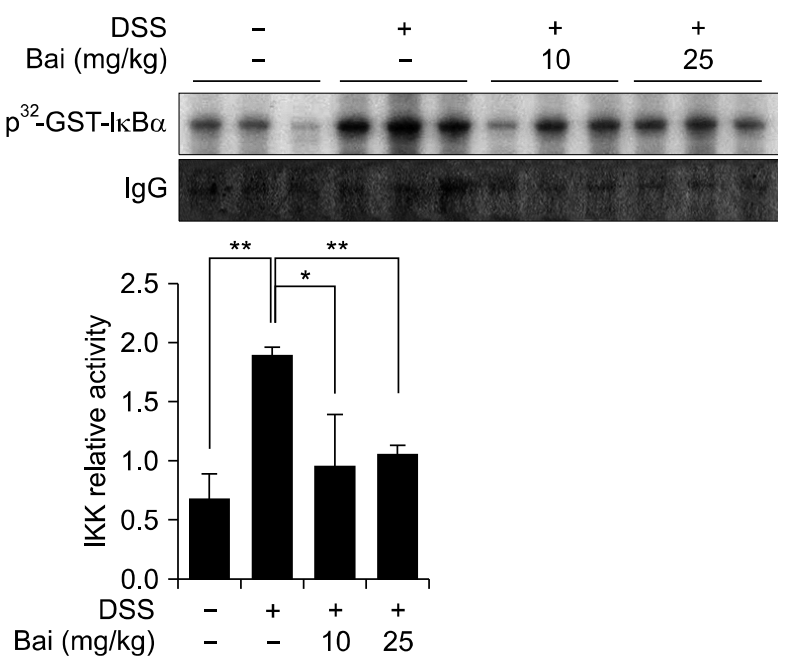

C
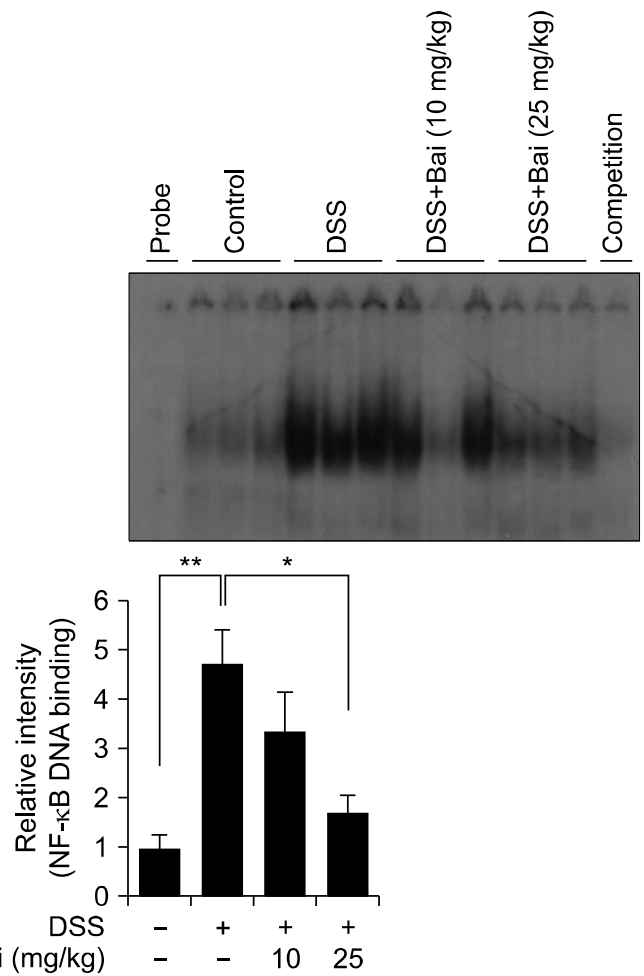

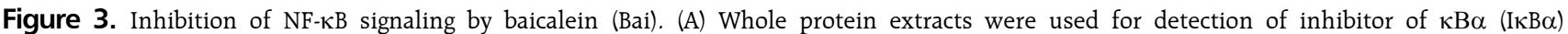

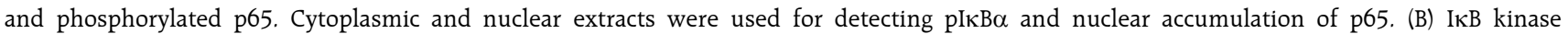
$\beta$ (IKK $\beta$ ) was precipitated with an anti-IKK $\beta$ antibody, followed by a kinase assay using IKB $\alpha$ as the substrate. The relative band intensity was normalized by the immunoglobulin G (IgG). (C) Nuclear extracts were incubated with the $\left[\gamma_{-}{ }^{32} \mathrm{P}\right]$-labeled polynucleotide probe containing the consensus motif of NF-KB. A subsequent electrophoresis was performed to separate protein-probe complexes from free probe. The relative DNA binding activity was calculated. Values are shown as means \pm SEM $(* P<0.05, * * P<0.01, * * * P<0.001)$. DSS, dextran sulfate sodium; GST, glutathione $\mathcal{S}$ transferase.

expression to a greater extent than those achieved with each compound alone (Fig. 5). The iNOS expression was not further enhanced by combination of both compounds.

\section{DISCUSSION}

Although there is outstanding investigation of chemotherapy and immunotherapy of colon cancer, most of patients may not be 
A
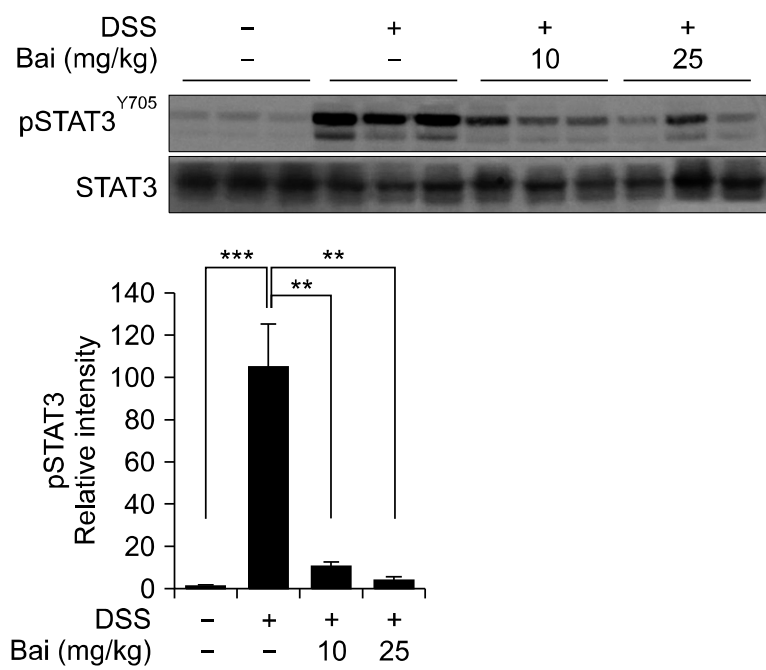

B

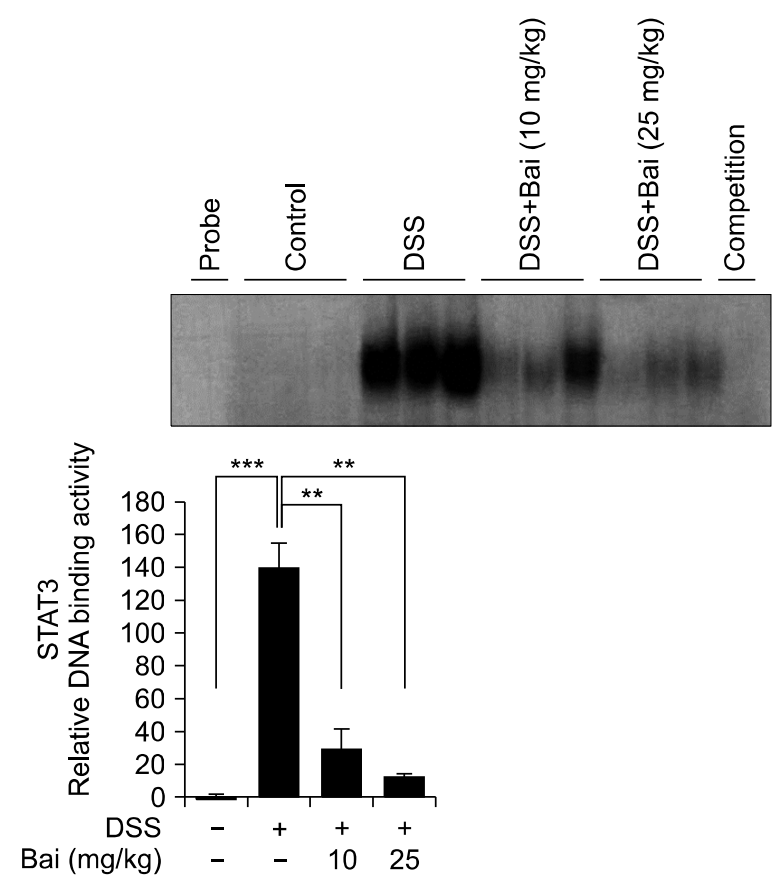

Figure 4. Baicalein (Bai) attenuated STAT3 signaling. (A) The protein levels of STAT3 and pSTAT3 were measured by Western blotting. (B) The DNA binding activity of STAT3 was measured by using a commercial double-strand polynucleotide containing STAT3 consensus motif. Electrophoresis mobility shift assay was conducted to separate the DNA-STAT3 complexes from free oligonucleotide as described in Materials and Methods. Data are expressed as means \pm SEM $(* * P<0.01, * * * P<0.001)$. DSS, dextran sulfate sodium.

diagnosed until they have noticeable symptoms. In that case, this disease may develop to an advanced stage that needs more complicated treatment and is not easily cured. Since IBD is associated with high risk in the development of colon cancer [39],
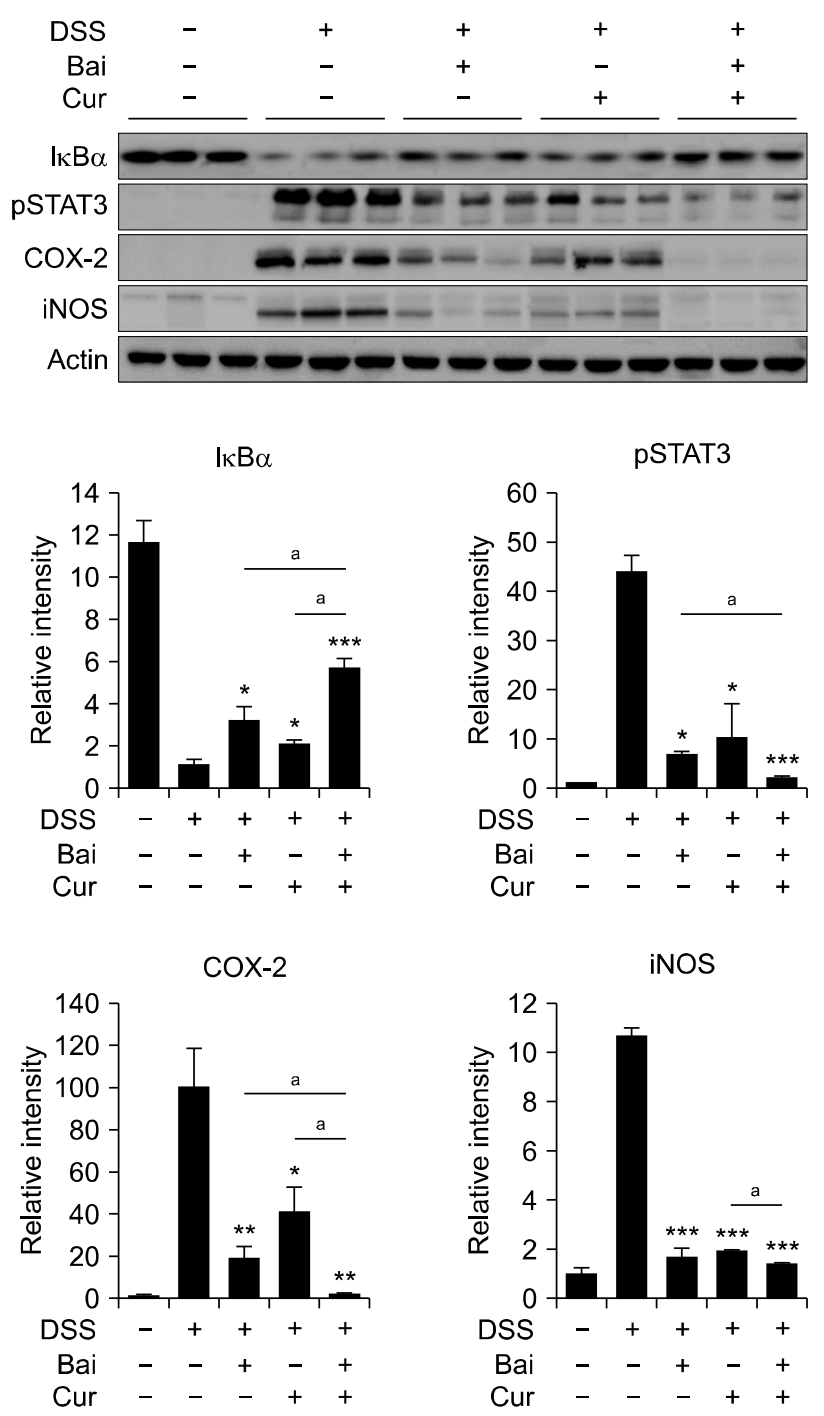

Figure 5. Synergistic effect of baicalein (Bai) and curcumin (Cur) on dextran sulfate sodium (DSS)-induced colitis. Mice were treated with either Bai $(25 \mathrm{mg} / \mathrm{kg})$ or Cur $(25 \mathrm{mg} / \mathrm{kg})$ or both in a combination for 7 days before the administration of DSS and for another 7 days together with DSS treatment. Inflammatory proteins were measured by Western blot analysis. Data are expressed as means \pm SEM $\left(* P<0.05, * * P<0.01,{ }^{* * *} P<0.001,{ }^{\text {a }} P<0.05\right)$. A single asterisk symbol represents statistically significant difference between the DSS treatment group plus single treatment with Bai or Cur and DSS only group; ${ }^{\mathrm{a}}$ The symbol represents statistically significant difference between combination of Bai and Cur and a single treatment of either compound). I $\mathrm{B} \alpha$, inhibitor of $\kappa \mathrm{B} \alpha$; iNOS, inducible nitric oxide synthase.

a great deal of concerns have been taken to prevent IBD in the management of colonic cancer. A group of nonsteroidal antiinflammatory drugs have been commonly used to treat IBD, but a prolonged application causes side effects including nausea, abdominal pain and gastritis [40].

A wide variety of dietary compounds, such as curcumin, 
<smiles>O=c1cc(-c2ccccc2)oc2cc(O)c(O)c(O)c12</smiles>

Curcumin

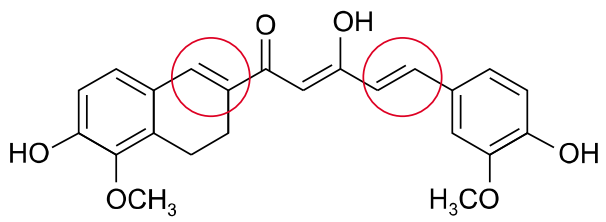

Figure 6. Chemical structures of baicalein and curcumin. Baicalein posesses functional diorthohydroxyl group and curcumin has electrophilic carbonyl groups.

resveratrol, gingerol and epigallocatechin gallate, have been recognized as safer compounds than synthetic nonsteroidal antiinflammatory drugs in inhibiting aberrant inflammatory signaling that often occurs during the carcinogenesis process [41]. Baicalein, an anti-inflammatory ingredient of a traditional Chinese medical plant $S$. baicalensis Georgi, has been shown to protect against DSS- or 2,4,6-trinitrobenzenesulfonic acidinduced colitis [30,32], but the underlying mechanisms remained largely unrevealed. We found that baicalein inhibits inflammation by suppressing NF-KB-mediated expression of COX-2 and iNOS. It down-regulates the kinase activity of IKK, thereby blocking the phosphorylation and degradation of IKB $\alpha$. The inhibition of IKK is mediated by an attenuation of the signal transduction through toll like receptor 4/myeloid differentiation primary response gene 88 [26]. Baicalein has been shown to suppress the activation of mitogen-activated protein kinases and Akt serine/threonine kinase [42] which are major regulators of NF-KB signaling. Since the crosstalk of STAT3 with NF-KB has been considered as a vicious cycle [36], the suppression of both signaling pathways is importance in preventing inflammation-associated carcinogenesis. Our results uncover that the phosphorylation of STAT3 is also inhibited by baicalein which is likely to be achieved through inhibition of an upstream Janus kinase [43].

Combination therapy has advantage for achieving successful treatment of many diseases by acting through different mechanisms. Curcumin, a compound possessing electrophilic carbonyl groups (Fig. 6), can react with cysteine residue(s) of STAT3, thereby suppressing the phosphorylation, dimerization, and nuclear translocation of STAT3 [44,45]. Unlike curcumin, baicalein carry out its anti-inflammatory functions through the prominent diorthohydroxyl group (Fig. 6) that can chelate active metal ions [46]. Notably, co-treatment of baicalein with curcumin exerts a synergistic effect on the inhibition of NF-KB and STAT3 signaling. However, the treatment of anti-inflammatory compounds before or at the beginning of experimental inflammation may weaken the host immune response against toxic stimuli, which may not be beneficial for resolution at later phase, although these compounds could ameliorate inflammatory symptoms [47]. Baicalein has been identified as inhibitor of 12/15-lipoxygenase enzymes [48] that orchestrate phagocytosis of apoptotic cells [49], therefore, it is likely to jeopardize tissue repair and homeostasis at the phase of resolution. A strategy to overcome this drawback is the combination of anti-inflammatory phytochemicals with pro-resolving mediators including resolvin D1 [50] and 15-deoxy$\Delta^{12,14}$-prostaglandin $\mathrm{J}_{2}$ [51] since pro-resolving lipids have been used for anti-tumor treatment [52-54].

In summary, baicalein ameliorated DSS-induced colitis by inhibiting NF-KB and STAT3 signaling pathways. This was mediated by a blocking the expression of downstream enzymes, COX-2 and iNOS, that are related to the induction of colitis. In combination with curcumin, baicalein has shown a synergistic effect on the expression of aforementioned pro-inflammatory enzymes. These findings suggest that baicalein might contribute to the prevention of colitis-associated cancer development.

\section{CONFLICTS OF INTEREST}

No potential conflicts of interest were disclosed.

\section{ACKNOWLEDGMENTS}

This research was supported by Univera Co., Ltd., the CAP 4 project.

\section{REFERENCES}

1. Tomasello G, Tralongo P, Damiani P, Sinagra E, Di Trapani B, Zeenny MN, et al. Dismicrobism in inflammatory bowel disease and colorectal cancer: changes in response of colocytes. World J Gastroenterol 2014:20:18121-30.

2. Wang D, Dubois RN. The role of COX-2 in intestinal inflammation and colorectal cancer. Oncogene 2010;29:781-8.

3. Menter DG, Schilsky RL, DuBois RN. Cyclooxygenase-2 and cancer treatment: understanding the risk should be worth the reward. Clin Cancer Res 2010;16:1384-90. 
4. Aktan F. iNOS-mediated nitric oxide production and its regulation. Life Sci 2004;75:639-53.

5. Keklikoglu N, Koray M, Kocaelli H, Akinci S. iNOS expression in oral and gastrointestinal tract mucosa. Dig Dis Sci 2008;53: 1437-42.

6. Virchow R. Cellular pathology. As based upon physiological and pathological histology. Lecture XVI--Atheromatous affection of arteries. 1858. Nutr Rev 1989;47:23-5.

7. Li Q, Withoff S, Verma IM. Inflammation-associated cancer: NF-kappaB is the lynchpin. Trends Immunol 2005;26:318-25.

8. Barnes PJ, Karin M. Nuclear factor-kappaB: a pivotal transcription factor in chronic inflammatory diseases. N Engl J Med 1997; 336:1066-71.

9. Tak PP, Firestein GS. NF-kappaB: a key role in inflammatory diseases. J Clin Invest 2001;107:7-11.

10. Li Q, Verma IM. NF-kappaB regulation in the immune system. Nat Rev Immunol 2002;2:725-34.

11. Schreiber S, Nikolaus S, Hampe J. Activation of nuclear factor kappa B inflammatory bowel disease. Gut 1998:42:477-84.

12. Sun SC, Xiao G. Deregulation of NF-kappaB and its upstream kinases in cancer. Cancer Metastasis Rev 2003:22:405-22.

13. Barker N, Ridgway RA, van Es JH, van de Wetering M, Begthel H, van den Born M, et al. Crypt stem cells as the cells-of-origin of intestinal cancer. Nature 2009;457:608-11.

14. Elyada E, Pribluda A, Goldstein RE, Morgenstern Y, Brachya G, Cojocaru G, et al. CKI $\alpha$ ablation highlights a critical role for $\mathrm{p} 53$ in invasiveness control. Nature 2011;470:409-13.

15. Yin J, Harpaz N, Tong Y, Huang Y, Laurin J, Greenwald BD, et al. p53 point mutations in dysplastic and cancerous ulcerative colitis lesions. Gastroenterology 1993;104:1633-9.

16. Foster SL, Hargreaves DC, Medzhitov R. Gene-specific control of inflammation by TLR-induced chromatin modifications. Nature 2007:447:972-8.

17. Aggarwal BB, Takada Y, Shishodia S, Gutierrez AM, Oommen OV, Ichikawa $\mathrm{H}$, et al. Nuclear transcription factor NF-kappa B: role in biology and medicine. Indian J Exp Biol 2004:42:341-53.

18. Hayden MS, Ghosh S. Shared principles in NF-kappaB signaling. Cell 2008;132:344-62.

19. Greten FR, Eckmann L, Greten TF, Park JM, Li ZW, Egan LJ, et al. IKKbeta links inflammation and tumorigenesis in a mouse model of colitis-associated cancer. Cell 2004:118:285-96.

20. Perkins ND. Post-translational modifications regulating the activity and function of the nuclear factor kappa B pathway. Oncogene 2006;25:6717-30.

21. Huynh J, Etemadi N, Hollande F, Ernst M, Buchert M. The JAK/STAT3 axis: a comprehensive drug target for solid malignancies. Semin Cancer Biol 2017:45:13-22.

22. Corvinus FM, Orth C, Moriggl R, Tsareva SA, Wagner S, Pfitzner EB, et al. Persistent STAT3 activation in colon cancer is associated with enhanced cell proliferation and tumor growth. Neoplasia 2005:7:545-55.

23. Sugimoto K. Role of STAT3 in inflammatory bowel disease. World J Gastroenterol 2008;14:5110-4.

24. Zhao Q, Chen XY, Martin C. Scutellaria baicalensis, the golden herb from the garden of Chinese medicinal plants. Sci Bull (Beijing) 2016;61:1391-8.

25. Yeh CH, Ma KH, Liu PS, Kuo JK, Chueh SH. Baicalein decreases hydrogen peroxide-induced damage to NG108-15 cells via upregulation of Nrf2. J Cell Physiol 2015;230:1840-51.
26. He X, Wei Z, Zhou E, Chen L, Kou J, Wang J, et al. Baicalein attenuates inflammatory responses by suppressing TLR4 mediated NF- $\mathrm{KB}$ and MAPK signaling pathways in LPS-induced mastitis in mice. Int Immunopharmacol 2015;28:470-6.

27. Miocinovic R, McCabe NP, Keck RW, Jankun J, Hampton JA, Selman SH. In vivo and in vitro effect of baicalein on human prostate cancer cells. Int J Oncol 2005;26:241-6.

28. Leung HW, Yang WH, Lai MY, Lin CJ, Lee HZ. Inhibition of 12-lipoxygenase during baicalein-induced human lung nonsmall carcinoma $\mathrm{H} 460$ cell apoptosis. Food Chem Toxicol 2007:45:403-11.

29. Takahashi H, Chen MC, Pham H, Angst E, King JC, Park J, et al. Baicalein, a component of Scutellaria baicalensis, induces apoptosis by Mcl-1 down-regulation in human pancreatic cancer cells. Biochim Biophys Acta 2011;1813:1465-74.

30. Hong T, Jin GB, Cho S, Cyong JC. Evaluation of the anti-inflammatory effect of baicalein on dextran sulfate sodium-induced colitis in mice. Planta Med 2002;68:268-71.

31. Dou W, Mukherjee S, Li H, Venkatesh M, Wang H, Kortagere S, et al. Alleviation of gut inflammation by $\mathrm{Cdx} 2 / \mathrm{Pxr}$ pathway in a mouse model of chemical colitis. PLoS One 2012;7:e36075.

32. Luo X, Yu Z, Deng C, Zhang J, Ren G, Sun A, et al. Baicalein ameliorates TNBS-induced colitis by suppressing TLR4/MyD88 signaling cascade and NLRP3 inflammasome activation in mice. Sci Rep 2017:7:16374.

33. Kim DH, Hossain MA, Kang YJ, Jang JY, Lee YJ, Im E, et al. Baicalein, an active component of Scutellaria baicalensis Georgi, induces apoptosis in human colon cancer cells and prevents AOM/DSS-induced colon cancer in mice. Int J Oncol 2013; 43:1652-8.

34. Lavi I, Levinson D, Peri I, Nimri L, Hadar Y, Schwartz B. Orally administered glucans from the edible mushroom Pleurotus pulmonarius reduce acute inflammation in dextran sulfate sodium-induced experimental colitis. Br J Nutr 2010;103:393-402.

35. Youn J, Lee JS, Na HK, Kundu JK, Surh YJ. Resveratrol and piceatannol inhibit iNOS expression and NF-kappaB activation in dextran sulfate sodium-induced mouse colitis. Nutr Cancer 2009; 61:847-54.

36. Grivennikov SI, Karin M. Dangerous liaisons: STAT3 and NF-kappaB collaboration and crosstalk in cancer. Cytokine Growth Factor Rev 2010;21:11-9.

37. Yang JY, Zhong X, Kim SJ, Kim DH, Kim HS, Lee JS, et al. Comparative effects of curcumin and tetrahydrocurcumin on dextran sulfate sodium-induced colitis and inflammatory signaling in mice. J Cancer Prev 2018;23:18-24.

38. Yang JY, Zhong X, Yum HW, Lee HJ, Kundu JK, Na HK, et al. Curcumin inhibits STAT3 signaling in the colon of dextran sulfate sodium-treated mice. J Cancer Prev 2013;18:186-91.

39. Terzić J, Grivennikov S, Karin E, Karin M. Inflammation and colon cancer. Gastroenterology 2010;138:2101-14.e5.

40. Wolfe MM, Lichtenstein DR, Singh G. Gastrointestinal toxicity of nonsteroidal antiinflammatory drugs. N Engl J Med 1999:340: 1888-99.

41. Surh YJ. Cancer chemoprevention with dietary phytochemicals. Nat Rev Cancer 2003;3:768-80.

42. Guo Z, Hu X, Xing Z, Xing R, Lv R, Cheng X, et al. Baicalein inhibits prostate cancer cell growth and metastasis via the caveolin-1/AKT/mTOR pathway. Mol Cell Biochem 2015;406:111-9.

43. Qi Z, Yin F, Lu L, Shen L, Qi S, Lan L, et al. Baicalein reduces lip- 
opolysaccharide-induced inflammation via suppressing JAK/STATs activation and ROS production. Inflamm Res 2013;62:845-55.

44. Lee YH, Song NY, Suh J, Kim DH, Kim W, Ann J, et al. Curcumin suppresses oncogenicity of human colon cancer cells by covalently modifying the cysteine 67 residue of SIRT1. Cancer Lett 2018:431:219-29.

45. Hahn YI, Kim SJ, Choi BY, Cho KC, Bandu R, Kim KP, et al. Curcumin interacts directly with the Cysteine 259 residue of STAT3 and induces apoptosis in H-Ras transformed human mammary epithelial cells. Sci Rep 2018;8:6409.

46. Li-Weber M. New therapeutic aspects of flavones: the anticancer properties of Scutellaria and its main active constituents Wogonin, Baicalein and Baicalin. Cancer Treat Rev 2009:35:57-68.

47. Fullerton JN, Gilroy DW. Resolution of inflammation: a new therapeutic frontier. Nat Rev Drug Discov 2016;15:551-67.

48. Xu J, Zhang Y, Xiao Y, Ma S, Liu Q, Dang S, et al. Inhibition of $12 / 15$-lipoxygenase by baicalein induces microglia $\operatorname{PPAR} \beta / \delta$ : a potential therapeutic role for CNS autoimmune disease. Cell Death Dis 2013;4:e569.

49. Uderhardt S, Herrmann M, Oskolkova OV, Aschermann S, Bicker $\mathrm{W}$, Ipseiz N, et al. 12/15-lipoxygenase orchestrates the clearance of apoptotic cells and maintains immunologic tolerance. Immunity 2012;36:834-46.

50. Lee HN, Kundu JK, Cha YN, Surh YJ. Resolvin D1 stimulates efferocytosis through p50/p50-mediated suppression of tumor necrosis factor- $\alpha$ expression. J Cell Sci 2013;126(Pt 17):4037-47.

51. Kim W, Lee HN, Jang JH, Kim SH, Lee YH, Hahn YI, et al. 15-Deoxy- $\Delta 12,14$-prostaglandin $\mathrm{J} 2$ exerts proresolving effects through nuclear factor E2-related factor 2-induced expression of CD36 and heme oxygenase-1. Antioxid Redox Signal 2017;27: 1412-31.

52. Zhong X, Lee HN, Surh YJ. RvD1 inhibits TNF $\alpha$-induced c-Myc expression in normal intestinal epithelial cells and destabilizes hyper-expressed c-Myc in colon cancer cells. Biochem Biophys Res Commun 2018:496:316-23.

53. Ye Y, Scheff NN, Bernabé D, Salvo E, Ono K, Liu C, et al. Anti-cancer and analgesic effects of resolvin D2 in oral squamous cell carcinoma. Neuropharmacology 2018;139:182-93.

54. Sulciner ML, Serhan CN, Gilligan MM, Mudge DK, Chang J, Gartung A, et al. Resolvins suppress tumor growth and enhance cancer therapy. J Exp Med 2018;215:115-40. 